\title{
Primary Care Management of Chronic Constipation in Asia: The ANMA Chronic Constipation Tool
}

\begin{abstract}
Kok-Ann Gwee, ${ }^{1 *}$ Uday C Ghoshal, ${ }^{2}$ Sutep Gonlachanvit, ${ }^{3}$ Andrew Seng Boon Chua, ${ }^{4}$ Seung-Jae Myung, ${ }^{5}$ Shaman Rajindrajith, ${ }^{6}$ Tanisa Patcharatrakul, ${ }^{3}$ Myung-Gyu Choi, ${ }^{7}$ Justin C Y Wu, ${ }^{8}$ Min-Hu Chen, ${ }^{9}$ Xiao-Rong Gong ${ }_{1}^{1,9}$ Ching-Liang Lu, ${ }^{10}$ Chien-Lin Chen, ${ }^{11}$ Nitesh Pratap, ${ }^{12}$ Philip Abraham, ${ }^{13}$ Xiao-Hua Hou, ${ }^{14}$ Meiyun Ke, ${ }^{15}$ Jane D Ricaforte-Campos, ${ }^{16}$ Ari Fahrial Syam ${ }^{17}$ and Murdani Abdullah"17

${ }^{1}$ Department of Medicine, Yong Loo Lin School of Medicine, National University of Singapore, Singapore; ${ }^{2}$ Department of Gastroenterology, Sanjay Gandhi Postgraduate Institute of Medical Sciences, Lucknow, India; ${ }^{3}$ GI Motility Research Unit, Division of Gastroenterology, Department of Medicine, Faculty of Medicine, Chulalongkorn University, Bangkok, Thailand; ${ }^{4}$ Department of Primary Care and Gastroenterology, Gastro Centre Ipoh, Ipoh, Perak, Malaysia; ' 5 Department of Gastroenterology, University of Ulsan College of Medicine, Asan Medical Center, Seoul, South Korea; ${ }^{6}$ Faculty of Medicine, University of Kelaniya, Ragama, Sri Lanka; ' Division of Gastroenterology, Department of Internal Medicine, Seoul St. Mary's Hospital, The Catholic University of Korea, Seoul, South Korea; ${ }^{8}$ Institute of Digestive Disease, The Chinese University of Hong Kong, Hong Kong SAR; ' Department of Gastroenterology and Hepatology, The First Affiliated Hospital, Sun Yat-Sen University, Guangzhou, Guangdong, China; ${ }^{10}$ Division of Gastroenterology, Taipei Veterans General Hospital; Institute of Brain Science, National Yang-Ming University Taipei, Taiwan; ${ }^{11}$ Department of Medicine, Buddhist Tzu Chi General Hospital and Tzu Chi University, Hualien, Taiwan; ${ }^{12}$ Asian Institute of Gastroenterology, Hyderabad, India; ${ }^{13}$ P D Hinduja National Hospital and MRC, Mahim, Mumbai, India; ${ }^{14}$ Department of Gastroenterology and Hepatology, Union Hospital of Tongii Medical College, Huazhong University of Science and Techonology, Wuhan, Hubei, China; ${ }^{15}$ Department of Gastroenterology, Peking Union Medical College Hospital, Chinese Academy of Medical Science, Beijing, China; ${ }^{16}$ Section of Gastroenterology, Department of Internal Medicine, Medical Center Manila, Manila, Philippines; and ${ }^{17}$ Division of Gastroenterology, Department of Internal Medicine, Cipto Mangunkusumo General Hospital/Faculty of Medicine, University of Indonesia, Jakarta, Indonesia
\end{abstract}

Chronic constipation (CC) may impact on quality of life. There is substantial patient dissatisfaction; possible reasons are failure to recognize underlying constipation, inappropriate dietary advice and inadequate treatment. The aim of these practical guidelines intended for primary care physicians, and which are based on Asian perspectives, is to provide an approach to CC that is relevant to the existing health-care infrastructure. Physicians should not rely on infrequent bowel movements to diagnose CC as many patients have one or more bowel movement a day. More commonly, patients present with hard stool, straining, incomplete feeling, bloating and other dyspeptic symptoms. Physicians should consider CC in these situations and when patients are found to use laxative containing supplements. In the absence of alarm features physicians may start with a 2-4 week therapeutic trial of available pharmacological agents including osmotic, stimulant and enterokinetic agents. Where safe to do so, physicians should consider regular (as opposed to on demand dosing), combination treatment and continuous treatment

Received: January 22, 2013 Revised: March 17, 2013 Accepted: March 20, 2013

(c) This is an Open Access article distributed under the terms of the Creative Commons Attribution Non-Commercial License (http://creativecommons. org/licenses/by-nc/3.0) which permits unrestricted non-commercial use, distribution, and reproduction in any medium, provided the original work is properly cited.

*Correspondence: Kok-Ann Gwee, FRCP, PhD

Stomach Liver and Bowel Center, Gleneagles Hospital, Annexe Block 05-37, 6A Napier Road, Singapore 258500, Singapore Tel: +65-6474-6848, Fax: +65-6475-8285, E-mail: slbclinic@gmail.com

Financial support: An unrestricted educational grant was received from Janssen Pharmaceuticals and Boehringer Ingelheim to support the organization of the meetings.

Conflicts of interest: Kok-Ann Gwee has received research grants from Abbott Laboratories and Janssen Pharmaceuticals, speaking honorarium from Abbott Laboratories, Janssen Pharmaceuticals and Boehringer Ingelheim International GmbH, and is on the scientific advisory board of Danone Research.

Author contributions: Detailed review of scientific literature: KA Gwee, UC Ghoshal, S Gonlachanvit, MG Choi, JCY Wu, MH Chen, S Rajindrajith, N Pratap, SJ Myung and CL Lu. Formulation of guidelines: ASB Chua, KA Gwee, UC Ghoshal, S Gonlachanvit, MH Chen, S Rajindrajith, CL Lu, CL Chen, P Abraham and JD Ricaforte-Campos. Preparation and review of manuscript: ASB Chua, KA Gwee, UC Ghoshal, S Gonlachanvit, MH Chen, S Rajindrajith, MG Choi, JCY Wu, N Pratap, XH Hou, M Ke, XR Gong, T Patcharatrakul, CL Lu, CL Chen, P Abraham, JD Ricaforte-Campos, AF Syam and M Abdullah. 
for at least 4 weeks. If patients do not achieve satisfactory response, they should be referred to tertiary centers for physiological evaluation of colonic transit and pelvic floor function. Surgical referral is a last resort, which should be considered only after a thorough physiological and psychological evaluation.

(J Neurogastroenterol Motil 2013;19:149-160)

\section{Key Words}

Asia; Constipation; Management; Physicians, primary care

\section{Introduction}

There is a perception that chronic constipation (CC) is an uncommon problem in Asia, and perhaps arising in part from this perception, the evaluation and management of this condition does not appear to be a priority in training programs for medical doctors. In 2 related global surveys, the prevalence of self-defined constipation in Asia (represented by South Korea, China and Indonesia) was estimated to be $15-23 \%$ in women and about $11 \%$ in men ${ }^{1,2}$ In comparison, the same survey found a lower prevalence in Germany, Italy and the UK for both women (7-11\%) and men $(<5 \%)$. In China, the health-related quality of life scores for community subjects with (against those without) CC were poorer across all domains. ${ }^{3}$ In Taiwan, significantly more doctor visits and absenteeism for gastrointestinal (GI) complaints were found in those with CC than those without. ${ }^{4}$ In Singapore, elderly men with CC were found to suffer more from lower urinary tract symptoms and erectile dysfunction than those without. ${ }^{5}$ Both in the West and in Asia, there are reports that a substantial number of constipation sufferers are dissatisfied with fiber supplements and over-the-counter laxatives. ${ }^{6-10}$

There are also important potential differences between Asia and the West in terms of patient perception and self-management, dietary practices, intestinal physiology and health-care infrastructure, that warrant the development of management guidelines based on Asian perspectives. In India patients, selfperceived constipation report a median of 2 bowel movements a day; here there is also a high level of dietary fiber intake in the general and patient population. ${ }^{11-13}$ People in China and India, both those who report and do not report constipation, appear to have relatively shorter colonic transit times than in the West. ${ }^{11,14-16}$ There is also a high level of lactase deficiency across all the major ethnic groups in Asia. ${ }^{17-19}$ In part, these dietary differences influence how people in Asia self-manage their constipation. $^{1,2,20}$
Therefore, the Asian Neurogastroenterology and Motility Association (ANMA) felt that there was a need for practical guidelines in the management of $\mathrm{CC}$ which take into account the disease epidemiology, socio-cultural factors and health-care infrastructure of Asia. As they are expected to be the first point of medical contact for most patients, these guidelines were developed with primary care physicians foremost in mind. The emphasis of our paper is on clinical practice, and as such, only the key relevant information will be presented to support our management recommendations. An in-depth review of the relevant literature will be presented in a follow-up publication.

\section{Methodology}

In the first phase, 8 experts were assigned to perform a detailed review of the literature on epidemiology (including symptoms, stool form), pathophysiology (including motility, organic causes), psychosocial (including diet and lifestyle) and treatment (including guidelines, pharmacological and non-pharmacological) related to constipation. These experts were tasked to pay particular attention to the Asian literature. The findings of these reviews were presented to 20 members of ANMA (representing 11 countries, including primary, secondary and tertiary care physicians) on September 30, 2011. In the course of these presentations, we identified aspects of the Asian patients' experiences of constipation which were not consistent with those in the West, and how these may have impacted on how physicians manage CC in Asia. A specific example was that the experts shared their common experience that a substantial number of patients referred to them for further management of bloating or fullness were found to have underlying $\mathrm{CC}$ that was untreated. The proceedings of this meeting were then reviewed again by the 8 experts. Finally a meeting was held on April 21-22, 2012 and an updated review of the key aspects of the Asian CC was presented to 14 ANMA members. From May to December 2012, email reviews and face to face discussions and presentations were made on the major 
points of the guidelines among the co-authors. All in all the work involved review and presentation involving 20 experts from China, India, Indonesia, South Korea, Thailand, Taiwan, Malaysia, Sri Lanka, the Philippines, Hong Kong and Singapore. These guidelines are intended as a practical approach for clinical management of $\mathrm{CC}$ in Asia, to provide relevant information to primary and secondary care physicians, and for $\mathrm{CC}$, and may not be applicable to recent or occasional constipation. For the purpose of these guidelines, $\mathrm{CC}$ is defined as the presence of recurrent or persistent symptoms of constipation occurring over a 3 -month period or longer. This definition does not assume to differentiate functional from organic causes of constipation. The term functional here encompasses the diagnoses such as slow transit constipation, irritable bowel syndrome (IBS) and pelvic floor dysfunction; it does not imply the Rome definition of functional constipation.

\section{Early Recognition of Chronic Constipation -}

Physicians commonly perceive constipation to mean infrequent bowel movements. However, for people in the community with constipation, the commonest symptoms were either having hard stools or having to strain at bowel movement. ${ }^{5-9,21}$ A feeling of incomplete evacuation and bloating were reported more commonly than infrequent bowel movements. Studies from China have also observed that the presence of dyspepsia, in particular, fullness was associated with an increased risk of CC. ${ }^{3,22}$ Among sufferers with constipation, bloating appears to be particularly bothersome and difficult to treat. ${ }^{6-9,23}$ Preliminary results from an ongoing study undertaken by ANMA in patients with $\mathrm{CC}$ criteria presenting for treatment at primary and secondary care clinics in India and China, suggest that these patient had frequently received proton pump inhibitor agents in their previous treatment. ${ }^{23}$ When we analyzed their symptomatology, bloating was found to be both the most common and the most bothersome complaint. It is unclear whether these patients had concomitant acid reflux or dyspepsia, however, only $26.2 \%$ patients reported satisfaction with their previous treatment, while $46.3 \%$ felt no change and $7.5 \%$ felt worse in their symptoms. ${ }^{23}$ In a study from the US, the highest dissatisfaction rating was for ineffective relief of bloating with fiber treatment. ${ }^{6-9}$ Dissatisfaction and inappropriate treatment may stem from failure to adequately recognize constipation and its manifestations. Recognition of constipation is challenging given that physicians, patients and physiologists disagree on what is constipation. Community studies from Singa- pore and from the US found that among subjects who fulfilled the same stringent criteria for $\mathrm{CC}$, one fifth or less actually perceived that they were constipated. ${ }^{5,24}$ A study from the UK has even found that the majority of women with evidence of slow colonic transit did not perceive constipation. ${ }^{25}$ In a study from India, $99 \%$ of people in the community passed one or more stools a day, and patients with a diagnosis of constipation had a median stool frequency of twice a day. ${ }^{12}$

To improve the efficiency of recognizing constipation, it is important to appreciate that some patients may not present with obvious defecation related complaints. Therefore, we have drawn up a list of alert symptoms which while they may not be part of standard international criteria for $\mathrm{CC}$, are nonetheless frequently associated with underlying constipation. In addition to the usual constipation symptoms, the list of alert symptoms (set out in Fig. 1) includes bloating, fullness, complaints of difficulty to pass stools, and the need for laxative containing medications or supplements. The alert symptoms list is different from the alarm symptoms list set out in Table 1. The alarm features checklist is to help physicians screen patients for possible organic disease or secondary causes of constipation (details discussed in the next section). If clinical evaluation has reasonably excluded organic disease, the physician should enquire specifically for the presence of any of

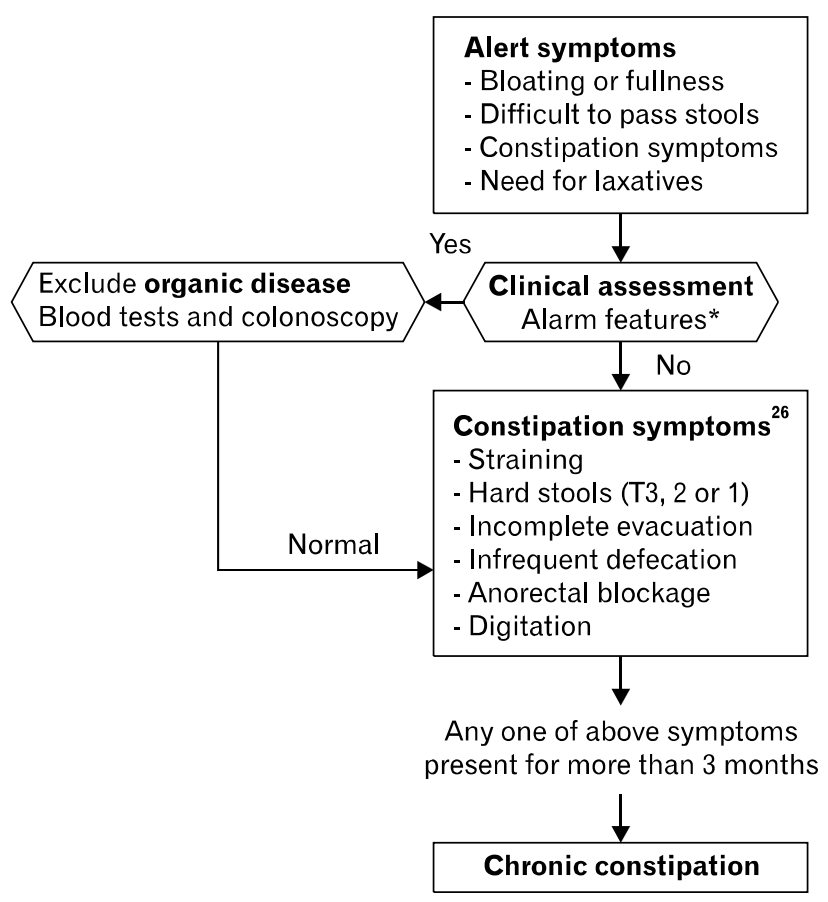

Figure 1. Diagnostic algorithm for chronic constipation. *See Table 1. 
Table 1. List of Alarm Features

\begin{tabular}{l} 
List of alarm features \\
\hline Age $\geq 45$ years \\
Change in stool caliber \\
Blood in stool \\
Unintended weight loss \\
Fever \\
Abdominal mass \\
Family history of gastrointestinal cancer \\
Iron-deficiency anemia \\
Recent onset constipation \\
Rectal bleeding \\
Rectal prolapse \\
Vomiting \\
Loss of appetite
\end{tabular}

the symptoms associated with CC according to the Rome III criteria. ${ }^{26}$ In addition, we encourage all physicians to show their patients the Bristol stool scale. We observed that in a number of studies from Asia, about $20-50 \%$ of patients with either functional constipation or IBS with constipation, perceived Bristol type 3 stool form to be hard stool. ${ }^{23,27,28}$ Therefore, we advise that patients who report Bristol types 1 to 3 stool forms should be carefully assessed for the other symptoms of constipation. We have found this to be an extremely useful tool to help patients and doctors recognize the association between dyspeptic symptoms and bowel disturbance.

\section{Clinical Evaluation}

Clinical evaluation should be based on a detailed history and a careful physical examination. Particular care should be taken to document the absence of alarm features, to record all drugs taken (in particular, use of opiates and codeine should be sought), and to include a digital rectal examination. However, secondary causes of CC are uncommon and the yield from laboratory investigations is likely to be low. We recommend that investigations should be carried out only for patients with identified risk factors. Thyroid hormones should only be measured if the patient shows overt signs of hyper- or hypo-activity, as it is extremely rare for thyroid dysfunction to be a cause of $\mathrm{CC}{ }^{29}$ Among constipated patients who visited a tertiary hospital in Korea, the prevalence of overt and subclinical hypothyroidism were respectively $0.41 \%$ (men, $0.36 \%$; women, $0.53 \%$ ), and $1.76 \%$ (men, $1.28 \%$; women $2.03 \%) .{ }^{30}$ We suggest that the elderly especially those who have concomitant medical conditions and medications, and those who have been prescribed a restrictive diet should be checked for hyponatremia and hypokalemia. With regards to colorectal cancer, a number of systematic reviews as well as prospective studies from the West provide evidence that constipation is not a predictive factor. ${ }^{31,32}$ Nonetheless, constipation is not a protective factor, and, there are data that severe constipation may impose an increased risk for colorectal cancer. ${ }^{33,34}$ Therefore we recommend an earlier age threshold for colonoscopy of age $\geq 45$ years for Japanese, Koreans and Chinese, and age $\geq 50$ years for Indians and Thais to align with the Asian IBS Consensus, and the Asia-Pacific colorectal cancer screening guidelines. ${ }^{35,36}$

\section{Dietary and Lifestyle Advice}

Community based as well as healthy volunteer studies generally support an effect for dietary fiber, fluid intake and physical exercise, on stool consistency and frequency. ${ }^{37,38}$ However, a distinction should be made between healthy subjects and patients with CC. When dietary fiber and fluid intake were measured objectively, studies have consistently demonstrated no significant differences between patients with $\mathrm{CC}$ and healthy controls. ${ }^{39-42}$ Furthermore, in the limited number of randomized controlled studies in idiopathic CC, the benefit of fiber treatment was inconclusive compared to placebo. ${ }^{43} \mathrm{We}$ wish to highlight also that excessive fiber intake is expected to aggravate bloating, flatulence and possibly abdominal cramps. ${ }^{41}$ In a study, $80 \%$ of constipated patients who received fiber were not completely satisfied with the ability of fiber to relieve their bloating while $50 \%$ thought fiber did not completely relieve their constipation. ${ }^{9}$ It is likely that most patient suffering with CC will already have received advice to increase intake of dietary fiber and fluids, and to undertake regular physical exercise. Therefore we advise that a formal evaluation of dietary fiber and fluid intake to be carried out, before recommending further increases in dietary fiber. The generally recommended daily dietary fiber intake in adults is $20-30 \mathrm{~g}$, and in children is calculated as age (in years) $+5 \mathrm{~g}{ }^{44}$ Bulking agents (e.g., isphagula, psyllium and polycarbophil) have similar physico-chemical properties to dietary fiber. These agents have been reported to produce better formed stool, but as with dietary fiber, the global response for patients with $\mathrm{CC}$ is expected to be similar to placebo, although they may be better tolerated. ${ }^{43} \mathrm{~A}$ number of studies have examined the effects of probiotic containing food supplements on GI transit and their potential for treating $\mathrm{CC}$, but the interpretation of these studies is confounded by heterogeneity in dose of probiotics, species of bacterium used, the evaluated 
clinical end points and study design. ${ }^{45-52}$ A potentially important confounding factor that has not been adequately addressed is whether fundamental differences in indigenous gut flora exists between peoples from different regions given differences in diet, hygiene levels and prevalence of lactose malabsorption. There are very few studies from Asia and their poor methodology do not allow us to discern whether the improvements reported derive from the presence of lactose malabsorption and from addition of fiber in the probiotic formulation. In south China, Yang et $\mathrm{al}^{45}$ randomly allocated 135 adult female patients with functional constipation, to consume either fermented milk product containing Bifidobacterium lactis DN-173 010 and yogurt starters (test product) or acidified milk containing non-living bacteria (control) for 2 weeks. During the first week of treatment, consumption of the test product appeared to be associated with a superior improvement in stool frequency and consistency, but during the second week of treatment, both treatments appeared to produce improvement in stool consistency. In South Korea, Choi et al ${ }^{46}$ randomly allocated 142 patients with constipation predominant IBS to receive either a multi-strain probiotic fermented milk with Streptococcus thermophilus, Lactobacillus acidophilus and Bifidobacterium infantis mixed with dietary fiber or the same probiotic fermented milk without fiber for 4 weeks. Superior improvement in stool frequency and straining were reported for the fiber-enhanced treatment.

\section{Pharmacological Treatments}

In patients where attention has already been given to possible contributing factors, it is reasonable to prescribe a course of pharmacological treatment before further evaluation. The main aim of the treatment trial is to achieve regular complete bowel movement. Secondary aim includes the relief of associated symptoms such as bloating, fullness, anorexia and abdominal pain. To ensure an adequate first line trial of treatment, key considerations include the duration of treatment, the dosing schedule and the type of agent used. The 3 major classes comprise osmotic, stimulant and enterokinetic agents. A fourth class known as colonic secretagogues, is new, and there are at least 2 agents (lubiprostone and linaclotide) undergoing clinical trials. One (lubiprostone) has been approved in the US, but its availability in the rest of the world is limited to a small number of countries. Table 2 presents a summary of the various agents, the dosing ranges and treatment durations reported in clinical trials.

\section{Osmotic Agents}

Lactulose, an osmotic laxative has long been available as a safe alternative for the treatment of $\mathrm{CC}$ in pregnant or lactating women, children and the elderly. Lactulose was superior to placebo in terms of mean bowel movement frequency per week in the 3 trials. ${ }^{53-55}$ Lactulose was also superior to ispaghula in terms of mean bowel movement frequency per week and a trend of causing less abdominal pain was observed. ${ }^{56}$ Recently it has also been appreciated that lactulose possibly has a prebiotic effect (i.e., supports the development of probiotic bacteria in the colon) that could contribute to improvement in bowel function. ${ }^{57}$ In an old study, it was observed that after one week treatment with lactulose $15 \mathrm{~mL}$ twice daily, consistently more patients continued to pro-

Table 2. Summary of the Various Agents of Chronic Constipation

\begin{tabular}{llllc}
\hline Category & Laxative & Population & Range of dosage & Duration of treatment \\
\hline Osmotic & PEG & Adults & $13-39 \mathrm{~g} /$ day & Upto $6 \mathrm{mo}$ \\
& & Children & $1-1.5 \mathrm{~g} / \mathrm{kg} /$ day (disimpaction dose) & Upto 7 day \\
& & $0.3-0.8 \mathrm{~g} / \mathrm{kg} /$ day (maintenance dose) & Upto $6 \mathrm{mo}$ \\
& Lactulose & Adults & $15-60 \mathrm{~mL}$ & $1-12 \mathrm{wk}$ \\
& & Children $(11-18 \mathrm{yr})$ & $15 \mathrm{~mL}$ twice daily & $4 \mathrm{wk}$ \\
& & Children $(6-10 \mathrm{yr})$ & $10 \mathrm{~mL}$ twice daily & $4 \mathrm{wk}$ \\
Stimulant & Magnesium hydroxide & Children $(1-5 \mathrm{yr})$ & $5 \mathrm{~mL}$ twice daily & $4 \mathrm{wk}$ \\
& Bisacodyl/picosulfate & Adults $(>65 \mathrm{yr})$ & $25 \mathrm{~mL} /$ day & $8 \mathrm{wk}$ \\
Enterokinetics & Prucalopride & Children $(6-14 \mathrm{yr})$ & $2.5-5 \mathrm{mg} /$ day & $4 \mathrm{wk}$ \\
& & Adults $(>65 \mathrm{yr})$ & $1 \mathrm{mg} / \mathrm{day}$ & $\mathrm{No} \mathrm{data}$ \\
& & Adults $(18-65 \mathrm{yr})$ & $2 \mathrm{mg} / \mathrm{day}$ & $12 \mathrm{wk}$
\end{tabular}

${ }^{a}$ For children, bisacodyl/picosulfate was only used as part of preparation to cleanse bowel.

PEG, polyethylene glycol. 
duce normal stools than when they had received stimulant laxatives. ${ }^{58}$ This suggests the potential for a "carry-over" effect with lactulose; it would be interesting to explore whether this arises from a prebiotic effect. Lactulose treatment may be associated with cramps, bloating and flatulence. ${ }^{59}$

Another group of osmotic laxatives are the formulations containing polyethylene glycol (PEG). High doses of PEG based formulations were originally used primarily for colon cleansing prior to colonoscopy. They have also been shown to be useful for fecal disimpaction in both children and the elderly. ${ }^{59-61}$ These formulations are now also used to treat CC. Daily doses of upto $17 \mathrm{~g}$ have been given for up to 6 months in adults. ${ }^{62,63}$ These are generally safe for use in children, pregnancy and the elderly. The most common side effect is diarrhea with liquid stools, which appears to be a function of the dose, occurring in upto $17 \%$ with single dose and upto $36 \%$ with double dose; thus patients have to be taught to titrate the dose according to their response. ${ }^{64}$ Some formulations contain sodium and potassium; it is unknown whether the small quantities present may give rise to hypernatremia and hyperkalemia in elderly and those with impaired renal functions. $^{64}$

Milk of magnesia (Magnesium hydroxide) is an osmotic laxative where the poorly absorbable magnesium ions cause water to be retained in the intestinal lumen; stimulation of cholecystokinin release and activation of constitutive nitric oxide synthase might also contribute to its laxative actions. ${ }^{65,66}$ The evidence for its efficacy from randomized control trial is limited. One crossover study in 64 chronic constipated patients aged 65 years or older revealed that magnesium hydroxide at mean dose of $25 \mathrm{~mL}$ daily for 8 weeks produced significantly more normal stool consistency, more frequent bowel movements and reduced requirement for bisacodyl treatment compared with bulk-laxative. ${ }^{67}$ Reporting of adverse events is limited. In view of the risk of hypermagnesemia, it should not be used in patients with renal impairment.

\section{Stimulant Agents}

For stimulant laxatives, the most well studied are bisacodyl and sodium picosulfate. Picosulfate is converted to the same active moiety as bisacodyl (bis- $[p$-hydroxyphenyl)-pyridyl-2-methane, BHPM $)^{68}$ and is available in a liquid form that allows dose titration. However, as picosulfate requires activation by intestinal bacteria action, its effect is less predictable than bisacodyl. In 2 recent high quality randomized clinical trials both picosulfate and bisacodyl have been given at an average dose of $10 \mathrm{mg}$ every night for upto 4 weeks, involving a total of 735 primary care patients with a mean 20 years history of constipation. ${ }^{68,69}$ Both compounds produced significantly more complete bowel movements per week than placebo. With bisacodyl, patients were able to achieve an impressive 5 complete spontaneous bowel movements per week, compared with 2 for placebo. ${ }^{69}$ Diarrhea was reported by about half of the patients on active treatment, but only $18 \%$ discontinued bisacodyl; hyponatremia was observed in only 1 patient $(0.4 \%)$. Improvement in quality of life, in terms of psychosocial discomfort, anxiety and physical discomfort, was superior on active treatment compared to placebo. Despite the widespread use of senna, there is actually no well-designed randomized controlled trial comparing its efficacy with placebo. In all the three published controlled trials, senna was given in combination with fiber. ${ }^{70-73}$ It should be noted that senna is a common ingredient in over the counter 'herbal teas,' which may account for the finding of melanosis coli in patients on what they perceive to be a harmless food supplement.

\section{Prokinetic Agents}

Among prokinetic compounds, domperidone, erythromycin, mosapride, itopride, cinitapride and levosulpiride, have activity predominantly on the upper GI tract, and at present there are no high quality trials that support a role for these agents in treating constipation. Only cisapride, tegaserod and prucalopride have clinically meaningful activity on the lower GI tract; these are more accurately described as enterokinetic agents. Unfortunately cardiovascular side effects have been associated with cisapride and tegaserod, and their availability is presently restricted. Prucalopride is a new enterokinetic agent that has been shown in clinical trials to produce significant improvements in bowel transit, bowel function, GI symptoms, and quality of life..$^{74-76}$ The benefits were maintained with continued use for up to 24 months. ${ }^{77}$ Prucalopride's high selectivity for the 5-hydroxytryptamine 4 receptor may explain its favorable safety and tolerability profiles, so that it has been approved in some countries for use in the elderly and in subjects with stable cardiovascular disease. A recent randomized clinical trial has demonstrated that the efficacy in Asian subjects is similar to the pivotal studies. ${ }^{28,74-76}$ Based on secondary endpoint analysis of data derived from the pivotal studies, it appears that prucalopride may have particular effect to improve bloating. $^{78}$

\section{Definition of Pharmacological Non-responder}

Patients who fail pharmacological treatment should be re- 


\section{Diet and lifestyle review}

Dietary fiber supplement or bulking agent to be prescribed only if fiber intake is insufficient; avoid if there is bloating Pharmacological agents

Consider osmotic, stimulant or enterokinetic as single or combination therapy according to severity, past experience

\section{2-4 weeks}

Review patient-satisfaction, stool form, alarm features. Decision to continue or discontinue treatment according to physician's judgment or patient's preference.

Keep in mind $>2$ weeks may be needed to assess response.

If failed 4 weeks' treatment, consider combination or

alternatives.

Keep patient under review.

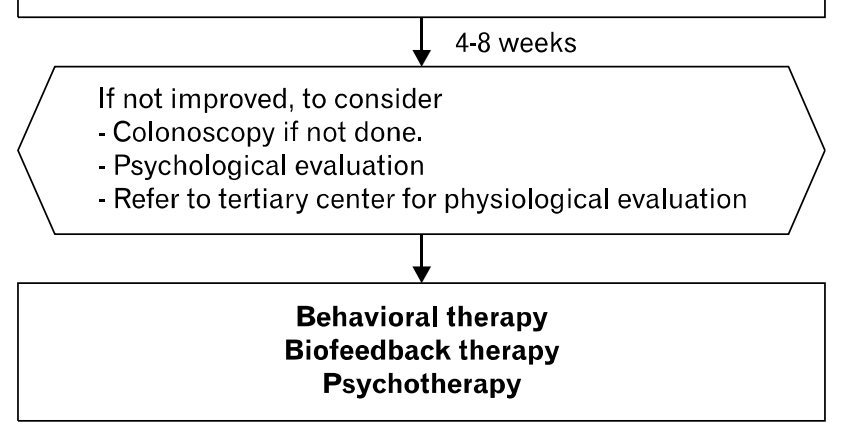

Figure 2. Chronic constipation treatment algorithm.

ferred to specialized centers for physiological laboratory evaluation (see Fig. 2). In the literature, there is no consistent definition of a non-responder. However, best quality data for currently available pharmacological treatment relates to bisacodyl and prucalopride. Therefore, we propose to extrapolate from the reported treatment protocols, ie bisacodyl at $10 \mathrm{mg}$ every night for at least 4 weeks, with consideration given to a total treatment period of up to 12 weeks if access to specialized centers is limited, or prucalopride at $2 \mathrm{mg}$ daily for up to 12 weeks. ${ }^{28,69,74-76}$ Combining a stimulant or prokinetic agent with an osmotic agent may also be considered.

\section{Non-pharmacological Treatments}

\section{Biofeedback and Behavioral Therapy}

Biofeedback is a training technique which aims to teach patients to relax, instead of contracting, their pelvic floor muscles during straining at stool. There are several variations of the method; involving in some, the use of visual or auditory signals from surface or electromyographic electrodes or anal probes, to inform patients whether they are performing the appropriate muscular action. In its most basic form, patients may also be trained to evacuate rectal contents by using a balloon, or even oatmeal porridge, in the shape of a stool, introduced into the rectum to simulate defecation. ${ }^{79,80}$ Currently biofeedback therapy is applied primarily to patients with pelvic floor dyssynergia (PFD) (alternative terms are anismus or obstructed defecation disorder). $\mathrm{Pa}$ tients with this condition demonstrate paradoxical contraction or inadequate relaxation of the pelvic floor muscles during attempted defecation; this is believed to be an acquired behavioral disorder of defecation. The prevalence of PFD among patients in Asia with severe intractable constipation is estimated to be between $21.7-34 \%$ based on reports from specialist centers in Bangkok and Seoul. ${ }^{81,82}$

Overall, biofeedback is a safe treatment which may produce durable improvement beyond the active treatment period. Randomized controlled trials in refractory CC patients with PFD have reported $70-80 \%$ success rates for upto one year. ${ }^{83-85} \mathrm{Im}-$ provement was reported for constipation symptoms, overall symptoms as well as dyssynergic pattern of defecation. However, the impact on quality of life or psychological state had not been clearly assessed. No uniform treatment protocol has been established as a wide variety of biofeedback techniques have been employed with insufficient data to determine the most effective modality. ${ }^{71,79,86-90}$ Limitations to its use in more patients include the limited availability of this resource; due in part to its requirements for equipment and trained therapist, and in part to reimbursement considerations. An important consideration is the ability of the therapist to communicate and interact well with the patient to establish a supportive relationship, as well as the time needed for instruction and learning. Few data of biofeedback therapy from Asian countries have been published with comparable response rate to the western studies. ${ }^{71,79,86-93}$

In view of its limited availability, we suggest that biofeedback is offered to patients with proven PFD as the most consistent benefits have been reported for this group. Symptoms and physical examination including digital rectal examination do not accurately predict which patient has PFD. Therefore, patients have to be referred to tertiary centers that have expertise to perform physiological laboratory evaluation of colonic transit time and pelvic floor function.

\section{Surgery}

A review of the literature (January 1995 to April 2012) from Asia carried out by this panel, has identified a total of 55 publications ${ }^{94,95}$ involving 2,545 patients, reporting the outcomes of 
surgical treatment for CC. The procedures described included subtotal colectomy with antiperistaltic cecoproctostomy, total colectomy with ileoproctostomy, laparoscopic total colectomy with cecorectal anastomosis for slow-transit constipation, and stapled transanal rectal resection for obstructed defecation syndrome associated with rectocele and rectal intussusception.

We advocate that enthusiasm for these surgical approaches should be tampered by observing the trends from the West, where our colleagues have informed us that in recent years they have almost never had to resort to surgery for their patients with functional constipation. ${ }^{96}$ Some of this reluctance is reflected in recent thoughtful reports from the West that suggests the possibility of a Munchaussen phenomenon operating in patients willing to subject themselves to an ablative procedure like colectomy. In a recent study from the US, it was reported that patients with constipation who had a history of sexual abuse had a ten-fold increased risk of surgery, and significantly poorer outcome if they underwent colectomy. ${ }^{97-100}$ In our review of Asian publications, it was disturbing to note that only 5 out of the 55 papers reported pre-operative psychiatric evaluation. ${ }^{101-105}$ Similarly, the most enthusiastic advocates from the West do not provide any psychiatric data on their patients. ${ }^{106,107}$

A number of recent studies found that the majority of patients with severe slow-transit constipation had evidence of small bowel motor abnormalities. ${ }^{108,109}$ We would also highlight the risk that some patients with $\mathrm{CC}$ who undergo colectomy may subsequently develop small intestinal obstruction possibly relating to small intestinal dysmotility. ${ }^{110,111}$ Our position is that any patient with functional constipation who is being considered for surgical intervention must undergo a formal psychiatric evaluation and an evaluation of upper GI motility, with at the minimum, measurement of small intestinal transit time.

\section{The Child and Adolescent Patient}

Abdominal pain is an important presenting complaint in children. ${ }^{112}$ Physicians should also enquire for presence of pain while passing stools, large diameter stools, stool withholding behavior and fecal incontinence. ${ }^{113}$ Several risk factors have been identified in children including low fiber diet, ${ }^{114}$ high consumption of junk food, ${ }^{115}$ stressful life events ${ }^{116}$ and living in urban areas. ${ }^{112}$ The majority of children have functional constipation and therefore laboratory investigations are usually not helpful unless features of organic diseases are evident in the clinical evaluation. Hypothyroidism presenting as isolated consti- pation is extremely rare. ${ }^{117}$ Although diet low in fiber has been identified as a risk factor, clinical trials have failed to demonstrate a clinically meaningful effect with fiber supplement. ${ }^{118,119}$ Medical management plays an important role specially in children as biofeedback therapy and behavioral intervention do not show any advantage over the conventional management. ${ }^{120,121}$ Unlike adults, over $90 \%$ of children with CC present with chronic fecal impaction. ${ }^{122}$ Therefore, the first step will usually require the withdrawal of dietary fiber while high dose PEG solutions (1-1.5 $\mathrm{g} / \mathrm{kg} /$ day for 3-4 days) are given to achieve disimpaction. ${ }^{122,123}$ This should be followed by judicial use of combination of osmotic and stimulant laxatives for the next 3-6 months to achieve regular bowel movements. Long-term follow-up is essential as about $15 \%$ of children progress to adulthood constipation. ${ }^{124}$

\section{Conclusion}

We have distilled the key practice-relevant information derived from a detailed study of the Asian literature as well as important mechanistic studies. These findings were then examined by our panel of physicians with experience practicing at primary and secondary care settings for their relevance to the health-care infrastructure in different parts of Asia. We have developed quick-reference flowcharts, safety checklists and prescription reference guide, to help clinicians make an early diagnosis of CC, institute first-line treatment and plan for follow-up actions. For future reference, this clinical tool will be named as the ANMA CC Tool.

\section{Acknowledgements}

We gratefully acknowledge the following organizations who provided unconditional sponsorship towards the development of the document: Janssen Pharmaceuticals and Boehringer Ingelheim International $\mathrm{GmbH}$.

\section{References}

1. Wald A, Scarpignato C, Mueller-Lissner S, et al. A multinational survey of prevalence and patterns of laxative use among adults with self-defined constipation. Aliment Pharmacol Ther 2008;28:917930.

2. Wald A, Mueller-Lissner S, Kamm MA, et al. Survey of laxative use by adults with self-defined constipation in South America and Asia: a comparison of six countries. Aliment Pharmacol Ther 2010; 31:274-284

3. Zhao YF, Ma XQ, Wang R, et al. Epidemiology of functional con- 
stipation and comparison with constipation-predominant irritable bowel syndrome: the Systematic Investigation of Gastrointestinal Diseases in China (SILC). Aliment Pharmacol Ther 2011;34: 1020-1029.

4. Lu CL, Chang FY, Chen CY, Luo JC, Lee SD. Significance of Rome II-defined functional constipation in Taiwan and comparison with constipation-predominant irritable bowel syndrome. Aliment Pharmacol Ther 2006;24:429-438.

5. Gwee KA, Siah KT, Wong RK, Wee S, Wong ML, Png DJ. Prevalence of disturbed bowel functions and its association with disturbed bladder and sexual functions in the male population. J Gastroenterol Hepatol 2012;27:1738-1744.

6. Ramkumar D, Rao SS. Efficacy and safety of traditional medical therapies for chronic constipation: systematic review. Am J Gastroenterol 2005;100:936-971.

7. Hungin AP, Tack J, Mearin F, Whorwell PJ, Dennis E, Barghout V. The truth in IBS (T-IBS) survey - Healthcare utilization and medication use among IBS patients in the USA. Am J Gastroenterol 2002;97:S281.

8. Schiller LR, Dennis E, Toth G. Primary care physicians consider constipation as a severe and bothersome medical condition that negatively impacts patients' lives. Am J Gastroenterol 2004;99:S234S235.

9. Johanson JF, Kralstein J. Chronic constipation: a survey of the patient perspective. Aliment Pharmacol Ther 2007;25:599-608.

10. Gwee KA, Setia S. Demographics and health care seeking behavior of Singaporean women with chronic constipation: implications for therapeutic management. Int J Gen Med 2012;5:287-302.

11. Tandon RK, Prasad N, Gupta MC, Tandon BN. Stool weights and transit time in North Indians. J Assoc Physicians India 1976; 24:807-810

12. Ghoshal UC, Abraham P, Bhatt C, et al. Epidemiological and clinical profile of irritable bowel syndrome in India: report of the Indian Society of Gastroenterology Task Force. Indian J Gastroenterol 2008;27:22-28.

13. Singh N, Makharia GK, Joshi YK. Dietary survey and total dietary fiber intake in patients with irritable bowel syndrome attending a tertiary referral hospital. Indian J Gastroenterol 2008;27:66-70.

14. Chan YK, Kwan AC, Yuen H, et al. Normal colon transit time in healthy Chinese adults in Hong Kong. J Gastroenterol Hepatol 2004;19:1270-1275.

15. Gwee K-A, Lu CL, Ghoshal UC. Epidemiology of irritable bowel syndrome in Asia: something old, something new, something borrowed. J Gastroenterol Hepatol 2009;24:1601-1607.

16. Ke MY, Li RQ, Pan GZ. [Gastrointestinal transit time (GITT) in normal Chinese and patients.] Zhonghua Nei Ke Za Zhi 1990;29: 723-726, 765. [Chinese]

17. Babu J, Kumar S, Babu P, Prasad JH, Ghoshal UC. Frequency of lactose malabsorption among healthy southern and northern Indian populations by genetic analysis and lactose hydrogen breath and tolerance tests. Am J Clin Nutr 2010;91:140-146.

18. Asmawi MZ, Seppo L, Vapaatalo H, Korpela R. Hypolactasia \& lactose intolerance among three ethnic groups in Malaysia. Indian J Med Res 2006;124:697-704.

19. Wang YG, Yan YS, Xu JJ, et al. Prevalence of primary adult lactose malabsorption in three populations of northern China. Hum Genet
1984;67:103-106.

20. Cheon JH, Yoon IJ, Myung SJ, et al. [Use of constipation remedies not prescribed by physician - a study of patients at a constipation clinic.] Kor J Neurogasroenterol Motil 2007;13:45-52. [Korean]

21. Pare P, Ferrazzi S, Thompson WG, Irvine EJ, Rance L. An epidemiological survey of constipation in canada: definitions, rates, demographics, and predictors of health care seeking. Am J Gastroenterol 2001;96:3130-3137.

22. Wang A, Liao X, Xiong L, et al. The clinical overlap between functional dyspepsia and irritable bowel syndrome based on Rome III criteria. BMC Gastroenterology 2008;8:43.

23. Gwee KA, Pratap N, Chen M, et al. Patients with chronic constipation attending outpatient clinics in India and China may present as functional dyspepsia and receive inappropriate treatment. Neurogastroenterol Motil 2012;24(suppl 2):114.

24. Talley NJ, Weaver AL, Zinsmeister AR, Melton LJ 3rd. Functional constipation and outlet delay: a population-based study. Gastroenterology 1993;105:781-790.

25. Probert CS, Emmett PM, Cripps HA, Heaton KW. Evidence for the ambiguity of the term constipation: the role of irritable bowel syndrome. Gut 1994;35:1455-1458.

26. Drossman DA. The functional gastrointestinal disorders and the Rome III process. Gastroenterology 2006;130:1377-1390.

27. Park JM, Choi MG, Cho YK, et al. Functional gastrointestinal disorders diagnosed by Rome III questionnaire in Korea. J Neurogastroenterol Motil 2011;17:279-286.

28. Ke M, Zou D, Yuan Y, et al. Prucalopride in the treatment of chronic constipation in patients from the Asia-Pacific region: a randomized, double-blind, placebo-controlled study. Neurogastroenterol Motil 2012;24:999.e541.

29. Baker JT, Harvey RF. Bowel habit in thyrotoxicosis and hypothyroidism. Br Med J 1971;1:322-323.

30. Kim J, Myung SJ, Yang D, et al. [Clinical characteristics of constipation with Hypothyroidism.] Intest Res 2010;8:48-57. [Korean]

31. Adelstein BA, Macaskill P, Chan SF, Katelaris PH, Irwig L. Most bowel cancer symptoms do not indicate colorectal cancer and polyps: a systematic review. BMC Gastroenterol 2011;11:65.

32. Astin M, Griffin T, Neal RD, Rose P, Hamilton W. The diagnostic value of symptoms for colorectal cancer in primary care: a systematic review. Br J Gen Pract 2011;61:e231-e243.

33. Roberts MC, Millikan RC, Galanko JA, Martin C, Sandler RS Constipation, laxative use, and colon cancer in a North Carolina population. Am J Gastroenterol 2003;98:857-864.

34. Kojima M, Wakai K, Tokudome S, et al. Bowel movement frequency and risk of colorectal cancer in a large cohort study of Japanese men and women. Br J Cancer 2004;90:1397-1401.

35. Gwee KA, Bak YT, Ghoshal UC, et al. Asian consensus on irritable bowel syndrome. J Gastroenterol Hepatol 2010;25:1189-1205.

36. Sung JJ, Lau JY, Young GP, et al. Asia Pacific consensus recommendations for colorectal cancer screening. Gut 2008;57:11661176.

37. Dukas L, Willett WC, Giovannucci EL. Association between physical activity, fiber intake, and other lifestyle variables and constipation in a study of women. Am J Gastroenterol 2003;98:17901796. 
38. Murakami K, Okubo H, Sasaki S. Dietary intake in relation to self-reported constipation among Japanese women aged 18-20 years. Eur J Clin Nutr 2006;60:650-657.

39. Nakaji S, Sugawara K, Saito D, et al. Trends in dietary fiber intake in Japan over the last century. Eur J Nutr 2002;41:222-227.

40. Murakami K, Sasaki S, Okubo H, et al. Association between dietary fiber, water and magnesium intake and functional constipation among young Japanese women. Eur J Clin Nutr 2007;61:616-622.

41. Muller-Lissner SA, Kamm MA, Scarpignato C, Wald A. Myths and misconceptions about chronic constipation. Am J Gastroenterol 2005;100:232-242.

42. Wong ML, Wee S, Pin CH, Gan GL, Ye HC. Sociodemographic and lifestyle factors associated with constipation in an elderly Asian community. Am J Gastroenterol 1999;94:1283-1291.

43. Suares NC, Ford AC. Systematic review: the effects of fibre in the management of chronic idiopathic constipation. Aliment Pharmacol Ther 2011;33:895-901.

44. Williams CL, Bollella M, Wynder EL. A new recommendation for dietary fiber in childhood. Pediatrics 1995;96(5 Pt 2):985-988.

45. Yang YX, He M, Hu G, et al. Effect of a fermented milk containing Bifidobacterium lactis DN-173010 on Chinese constipated women. World J Gastroenterol 2008;14:6237-6243.

46. Choi SC, Kim BJ, Rhee PL, et al. Probiotic fermented milk containing dietary fiber has additive effects in IBS with constipation compared to plain probiotic fermented milk. Gut Liver 2011;5:2228.

47. Agrawal A, Houghton LA, Morris J, et al. Clinical trial: the effects of a fermented milk product containing Bifidobacterium lactis DN-173 010 on abdominal distension and gastrointestinal transit in irritable bowel syndrome with constipation. Aliment Pharmacol Ther 2009;29:104-114.

48. Bu LN, Chang MH, Ni YH, Chen HL, Cheng CC. Lactobacillus casei rhamnosus Lcr35 in children with chronic constipation. Pediatr Int 2007;49:485-490.

49. Banaszkiewicz A, Szajewska H. Ineffectiveness of Lactobacillus GG as an adjunct to lactulose for the treatment of constipation in children: a double-blind, placebo-controlled randomized trial. J Pediatr 2005;146:364-369.

50. Riezzo G, Orlando A, D'Attoma B, et al. Randomised clinical trial: efficacy of Lactobacillus paracasei-enriched artichokes in the treatment of patients with functional constipation - a double-blind, controlled, crossover study. Aliment Pharmacol Ther 2012;35:441450 .

51. Koebnick C, Wagner I, Leitzmann P, Stern U, Zunft HJ. Probiotic beverage containing Lactobacillus casei Shirota improves gastrointestinal symptoms in patients with chronic constipation. Can J Gastroenterol 2003;17:655-659.

52. Meance S LC, Antoine JM. Recent advances in the use of functional foods: effects of the commercial fermented milk with Bifidobacterium animalis strain DN - 173010 and yoghurt strains on gut transit time in the elderly. Microb Ecol Health Dis 2003;15:15-22.

53. Wesselius-De Casparis A, Braadbaart S, Bergh-Bohlken GE, Mimica M. Treatment of chronic constipation with lactulose syrup: results of a double-blind study. Gut 1968;9:84-86.

54. Sanders JF. Lactulose syrup assessed in a double-blind study of elderly constipated patients. J Am Geriatr Soc 1978;26:236-239.
55. Bass $\mathrm{P}$, Dennis $\mathrm{S}$. The laxative effects of lactulose in normal and constipated subjects. J Clin Gastroenterol 1981;3(suppl 1):23-28.

56. Rouse M, Chapman N, Mahapatra M, Grillage M, Atkinson SN, Prescott P. An open, randomised, parallel group study of lactulose versus ispaghula in the treatment of chronic constipation in adults. Br J Clin Pract 1991;45:28-30.

57. Macfarlane S, Macfarlane GT, Cummings JH. Review article: prebiotics in the gastrointestinal tract. Aliment Pharmacol Ther 2006;2 4:701-714.

58. Connolly P, Hughes IW, Ryan G. Comparison of "Duphalac" and "irritant" laxatives during and after treatment of chronic constipation: a preliminary study. Curr Med Res Opin 1974;2:620625.

59. Lee-Robichaud H, Thomas K, Morgan J, Nelson RL. Lactulose versus polyethylene glycol for chronic constipation. Cochrane Database Syst Rev 2010;(7):CD007570.

60. Culbert P, Gillett H, Ferguson A. Highly effective new oral therapy for faecal impaction. Br J Gen Pract 1998;48:1599-1600.

61. Chen CC, Su MY, Tung SY, Chang FY, Wong JM, Geraint M. Evaluation of polyethylene glycol plus electrolytes in the treatment of severe constipation and faecal impaction in adults. Curr Med Res Opin 2005;21:1595-1602.

62. Dipalma JA, Cleveland MV, McGowan J, Herrera JL. A randomized, multicenter, placebo-controlled trial of polyethylene glycol laxative for chronic treatment of chronic constipation. Am J Gastroenterol 2007;102:1436-1441.

63. Paille F CN, Alleaume B, Vicari F. An open six-month study of the safety of Transipeg for treating constipation in community medicine. J Clin Res 1999;2:65-76.

64. Chaussade S, Minić M. Comparison of efficacy and safety of two doses of two different polyethylene glycol-based laxatives in the treatment of constipation. Aliment Pharmacol Ther 2003;17:165172.

65. Izzo AA, Gaginella TS, Mascolo N, Capasso F. Nitric oxide as a mediator of the laxative action of magnesium sulphate. Br J Pharmacol 1994;113:228-232.

66. Izzo AA, Gaginella TS, Capasso F. The osmotic and intrinsic mechanisms of the pharmacological laxative action of oral high doses of magnesium sulphate. Importance of the release of digestive polypeptides and nitric oxide. Magnes Res 1996;9:133-138.

67. Kinnunen O, Salokannel J. Constipation in elderly long-stay patients: its treatment by magnesium hydroxide and bulk-laxative. Ann Clin Res 1987;19:321-323.

68. Mueller-Lissner S, Kamm MA, Wald A, et al. Multicenter, 4-week, double-blind, randomized, placebo-controlled trial of sodium picosulfate in patients with chronic constipation. Am J Gastroenterol 2010;105:897-903.

69. Kamm MA, Mueller-Lissner S, Wald A, Richter E, Swallow R, Gessner U. Oral bisacodyl is effective and well-tolerated in patients with chronic constipation. Clin Gastroenterol Hepatol 2011;9:577583.

70. Passmore AP, Davies KW, Flanagan PG, Stoker C, Scott MG. A comparison of Agiolax and lactulose in elderly patients with chronic constipation. Pharmacology 1993;47(suppl 1):249-252.

71. Lee BH, Kim N, Kang SB, et al. The long-term clinical efficacy of biofeedback therapy for patients with constipation or fecal inconti- 
nence. J Neurogastroenterol Motil 2010;16:177-185.

72. Passmore AP, Wilson-Davies K, Stoker C, Scott ME. Chronic constipation in long stay elderly patients: a comparison of lactulose and a senna-fibre combination. BMJ 1993;307:769-771.

73. Marlett JA, Li BU, Patrow CJ, Bass P. Comparative laxation of psyllium with and without senna in an ambulatory constipated population. Am J Gastroenterol 1987;82:333-337.

74. Tack J, van Outryve M, Beyens G, Kerstens R, Vandeplassche L. Prucalopride (Resolor) in the treatment of severe chronic constipation in patients dissatisfied with laxatives. Gut 2009;58:357365.

75. Camilleri M, Kerstens R, Rykx A, Vandeplassche L. A placebo-controlled trial of prucalopride for severe chronic constipation. N Engl J Med 2008;358:2344-2354.

76. Quigley EM, Vandeplassche L, Kerstens R, Ausma J. Clinical trial: the efficacy, impact on quality of life, and safety and tolerability of prucalopride in severe chronic constipation - a 12-week, randomized, double-blind, placebo-controlled study. Aliment Pharmacol Ther 2009;29:315-328.

77. Camilleri M, Van Outryve MJ, Beyens G, Kerstens R, Robinson P, Vandeplassche L. Clinical trial: the efficacy of open-label prucalopride treatment in patients with chronic constipation - follow-up of patients from the pivotal studies. Aliment Pharmacol Ther 2010; 32:1113-1123.

78. Kerstens R, Vandeplassche L, Dubois D, Wouters L. Response of chronic constipation symptoms to prucalopride treatment and relationship with patient satisfaction. Gut 2011;60:A159.

79. Bleijenberg G, Kuijpers HC. Treatment of the spastic pelvic floor syndrome with biofeedback. Dis Colon Rectum 1987;30:108-111.

80. Lestar B, Penninckx F, Kerremans R. Biofeedback defaecation training for anismus. Int J Colorectal Dis 1991;6:202-207.

81. Gonlachanvit S, Patcharatrakul T. Causes of idiopathic constipation in Thai patients: associations between the causes and constipation symptoms as defined in the Rome II criteria. J Med Assoc Thai 2004;87(suppl 2):S22-S28.

82. Kim DH, Myung SJ, Yang SK, et al. [Clinical parameters for differentiating pelvic floor dyssynergia (PFD) in constipated patients.] Korean J Gastroenterol Motil 2002;8:167-176. [Korean]

83. Chiarioni G, Whitehead WE, Pezza V, Morelli A, Bassotti G. Biofeedback is superior to laxatives for normal transit constipation due to pelvic floor dyssynergia. Gastroenterology 2006;130:657664.

84. Heymen S, Scarlett Y, Jones K, Ringel Y, Drossman D, Whitehead WE. Randomized, controlled trial shows biofeedback to be superior to alternative treatments for patients with pelvic floor dyssynergiatype constipation. Dis Colon Rectum 2007;50:428-441.

85. Rao SS, Seaton K, Miller M, et al. Randomized controlled trial of biofeedback, sham feedback, and standard therapy for dyssynergic defecation. Clin Gastroenterol Hepatol 2007;5:331-338.

86. Glia A, Gylin M, Gullberg K, Lindberg G. Biofeedback retraining in patients with functional constipation and paradoxical puborectalis contraction: comparison of anal manometry and sphincter electromyography for feedback. Dis Colon Rectum 1997;40:889-895.

87. Heymen S, Wexner SD, Vickers D, Nogueras JJ, Weiss EG, Pikarsky AJ. Prospective, randomized trial comparing four biofeedback techniques for patients with constipation. Dis Colon Rectum
1999;42:1388-1393.

88. Koutsomanis D, Lennard-Jones JE, Roy AJ, Kamm MA. Controlled randomised trial of visual biofeedback versus muscle training without a visual display for intractable constipation. Gut 1995;37: 95-99.

89. Park DH, Myung SJ, Yoon IJ, et al. [Clinical factors associated with response to biofeedback therapy for patients with chronic constipation.] Korean J Gastroenterol 2003;42:289-296. [Korean]

90. Yang DH, Myung SJ, Jung KW, et al. Anorectal function and the effect of biofeedback therapy in ambulatory spinal cord disease patients having constipation. Scand J Gastroenterol 2010;45:12811288.

91. Patcharatrakul T, Gonlachanvit S. Outcome of biofeedback therapy in dyssynergic defecation patients with and without irritable bowel syndrome. J Clin Gastroenterol 2011;45:593-598.

92. Zhu FF, Lin Z, Lin L, Wang MF. Changes in quality of life during biofeedback for people with puborectalis dyssynergia: generic and disease-specific measures. J Adv Nurs 2011;67:1285-1293.

93. Shin JK, Cheon JH, Kim ES, et al. Predictive capability of anorectal physiologic tests for unfavorable outcomes following biofeedback therapy in dyssynergic defecation. J Korean Med Sci 2010; 25:1060-1065

94. Arebi N, Kalli T, Howson W, Clark S, Norton C. Systematic review of abdominal surgery for chronic idiopathic constipation. Colorectal Dis 2011;13:1335-1343.

95. Kumar A, Lokesh H, Ghoshal UC. Successful outcome of refractory chronic constipation by surgical treatment: a series of 34 patients. J Neurogastroenterol Motil 2013;19:78-84.

96. Tack J, Müller-Lissner S, Stanghellini V, et al. Diagnosis and treatment of chronic constipation - a European perspective. Neurogastroenterol Motil 2011;23:697-710.

97. O'Brien S, Hyman N, Osler T, Rabinowitz T. Sexual abuse: a strong predictor of outcomes after colectomy for slow-transit constipation. Dis Colon Rectum 2009;52:1844-1847.

98. FitzHarris GP, Garcia-Aguilar J, Parker SC, et al. Quality of life after subtotal colectomy for slow-transit constipation: both quality and quantity count. Dis Colon Rectum 2003;46:433-440.

99. El-Tawil AM. Persistence of abdominal symptoms after successful surgery for idiopathic slow transit constipation. South Med J 2002; 95:1042-1046

100. Zutshi M, Hull TL, Trzcinski R, Arvelakis A, Xu M. Surgery for slow transit constipation: are we helping patients? Int J Colorectal Dis 2007;22:265-269.

101. Tang WZ, Tang ZJ. [Surgical therapy for slow transit constipation.] Guanxi Yi Ke Da Xue Xue Bao 2003;20:423-424. [Chinese]

102. Gong XC, Zhu XH, Wang F, et al. Evaluation of colon slow transit constipation. Int J Surg 2008;35:813-817.

103. Qian Q, Jiang CQ, Zhang YJ, et al. [Comparison of subtotal colectomy with antiperistaltic cecoproctostomy and total colectomy with ileoproctostomy in treating slow transit constipation.] Zhonghua Wai Ke Za Zhi 2009;47:1849-1852. [Chinese]

104. Wei D, Zhao T, Cai J, Zhang H, Zhang JF. [Laparoscopic total colectomy with cecorectal anastomosis for slow-transit constipation.] Zhonghua Wei Chang Wai Ke Za Zhi 2010;13:157-159. [Chinese]

105. Zhao F, Li HY. [Surgical therapy for slow transit constipation.] 
Tianjin Yi Yao 2005;33:791-793. [Chinese]

106. Hassan I, Pemberton JH, Young-Fadok TM, et al. Ileorectal anastomosis for slow transit constipation: long-term functional and quality of life results. J Gastrointest Surg 2006;10:1330-1336; discussion 1336-1337.

107. Pikarsky AJ, Singh JJ, Weiss EG, Nogueras JJ, Wexner SD. Long-term follow-up of patients undergoing colectomy for colonic inertia. Dis Colon Rectum 2001;44:179-183.

108. Seidl H, Gundling F, Pehl C, Pfeiffer A, Schepp W, Schmidt T. Small bowel motility in functional chronic constipation. Neurogastroenterol Motil 2009;21:1278.e122.

109. Zarate N, Knowles CH, Yazaki E, Lunnis PJ, Scott SM. Clinical presentation and patterns of slow transit constipation do not predict coexistent upper gut dysmotility. Dig Dis Sci 2009;54:122-131.

110. Glia A, Akerlund JE, Lindberg G. Outcome of colectomy for slow-transit constipation in relation to presence of small-bowel dysmotility. Dis Colon Rectum 2004;47:96-102.

111. Preston DM, Hawley PR, Lennard-Jones JE, Todd IP. Results of colectomy for severe idiopathic constipation in women (Arbuthnot Lane's disease). Br J Surg 1984;71:547-552.

112. Rajindrajith S, Devanarayana NM, Adhikari C, Pannala W, Benninga MA. Constipation in children: an epidemiological study in Sri Lanka using Rome III criteria. Arch Dis Child 2012;97:4345.

113. Rasquin A, Di Lorenzo C, Forbes D, et al. Childhood functional gastrointestinal disorders: child/adolescent. Gastroenterology 2006; 130:1527-1537.

114. Lee WT, Ip KS, Chan JS, Lui NW, Young BW. Increased prevalence of constipation in pre-school children is attributable to under-consumption of plant foods: a community-based study. J Paediatr Child Health 2008;44:170-175.

115. Tam YH, Li AM, So HK, et al. Socioenvironmental factors asso- ciated with constipation in Hong Kong children and Rome III criteria. J Pediatr Gastroenterol Nutr 2012;5 5:56-61.

116. Devanarayana NM, Rajindrajith S. Association between constipation and stressful life events in a cohort of Sri Lankan children and adolescents. J Trop Pediatr 2010;56:144-148.

117. Bennett WE Jr, Heuckeroth RO. Hypothyroidism is a rare cause of isolated constipation. J Pediatr Gastroenterol Nutr 2012;54:285287.

118. Loening-Baucke V, Miele E, Staiano A. Fiber (glucomannan) is beneficial in the treatment of childhood constipation. Pediatrics 2004;113(3 Pt 1):e259-e264.

119. Castillejo G, Bulló M, Anguera A, Escribano J, Salas-Salvado J. A controlled, randomized, double-blind trial to evaluate the effect of a supplement of cocoa husk that is rich in dietary fiber on colonic transit in constipated pediatric patients. Pediatrics 2006;118:e641e648.

120. van Dijk M, Bongers ME, de Vries GJ, Grootenhuis MA, Last $\mathrm{BF}$, Benninga MA. Behavioral therapy for childhood constipation: a randomized, controlled trial. Pediatrics 2008;121:e1334-e1341.

121. van der Plas RN, Benninga MA, Buller HA, et al. Biofeedback training in treatment of childhood constipation: a randomised controlled study. Lancet 1996;348:776-780.

122. Benninga MA, Voskuijl WP, Taminiau JA. Childhood constipation: is there new light in the tunnel? J Pediatr Gastroenterol Nutr 2004;39:448-464.

123. Candy DC, Edwards D, Geraint M. Treatment of faecal impaction with polyethelene glycol plus electrolytes $(\mathrm{PGE}+\mathrm{E}$ ) followed by a double-blind comparison of PEG $+\mathrm{E}$ versus lactulose as maintenance therapy. J Pediatr Gastroenterol Nutr 2006;43:65-70.

124. van Ginkel R, Reitsma JB, Büller HA, van Wijk MP, Taminiau JA, Benninga MA. Childhood constipation: longitudinal follow-up beyond puberty. Gastroenterology 2003;125:357-363. 